\author{
И. Н. Сидоренко \\ Белорусский государственный университет
}

\title{
АРХЕТИПЫ КОЛЛЕКТИВНОГО БЕССОЗНАТЕЛЬНОГО И ПРОБЛЕМА НАСИЛИЯ В ФИЛОСОФИИ К. ЮНГА
}

В статье раскрывается и анализируется связь деструктивной природы человека с возникновением общества массовой культуры. В качестве методологии исследования выступила концепция коллективного бессознательного К. Юнга. Актуализация архетипа «Тень», воплощающего базовые инстинкты и ищущего выход для разрядки в различных формах социальной деструкции, дала возможность определить насилие как результат игнорируемого бессознательного. В качестве одной из главных характеристик массового общества была определена потеря гармонии сознания с бессознательным, что выразилось в массовизации сознания и поведения людей, растворении личности в толпе, ощущении внутренней дисгармонии. Причиной нарушения психического баланса выступает тотальная рационализация и формализация общественных отношений. Игнорирование и подавление бессознательного требует компенсации: стремление снять невроз как за счет идентификации индивидуального сознания с коллективным, так и посредством сублимации иррациональных влечений. Результатом такой компенсации выступает псевдополитическая активность, которая не предполагает разумного выбора и осознанного действия. Это приводит к невротизации, которая может получить форму психической эпидемии. В силу чего любое событие, выводящее из равновесия социальную систему, грозит обернуться и оборачивается разрушительным поведением масс. Опасность такой разрядки повышается в современном информационном обществе. В качестве вывода отмечается, что «Тень» выступает как моральная проблема, бросающая вызов «Я» и неосознаваемая без нравственных усилий. Поэтому первым шагом к ее осознанию становится признание реальности своих темных сторон.

Ключевые слова: коллективное бессознательное, архетип «Тень», насилие, деструкция, массовое общество, информационное общество.

Для цитирования: Сидоренко И. Н. Архетипы коллективного бессознательного и проблема насилия в философии К. Юнга // Труды БГТУ. Сер. 6, История, философия. 2021. № 1 (245). C. 134-137.

\section{N. Sidorenko \\ Belarusian State University \\ ARCHETYPES OF THE COLLECTIVE UNCONSCIOUS AND THE PROBLEM OF VIOLENCE IN PHILOSOPHY OF C. JUNG}

In this article the author reveals and analyzes the relationship between the destructive nature of man and the emergence of mass culture society. The methodology of the research is the concept of the collective unconscious C. Jung. The author actualizes the archetype "Shadow", which embodies the basic instincts and seeks a way to discharge in various forms of social destruction. This enabled the author of the article to define violence as the result of an ignored unconscious. As one of the main characteristics of mass society was defined as a loss of harmony of consciousness with the unconscious, which resulted in massivization of consciousness and human behavior, the dissolution of the individual in the crowd, the feeling of inner disharmony. The cause of impaired mental balance is the total rationalization and formalization of social relations. The disregard and suppression of the unconscious requires compensation: the desire to remove neurosis due to both identification of individual consciousness with the collective, and through sublimation of the irrational appetites. The result of this compensation acts as a pseudopolitical activity that does not involve a reasonable choice and conscious action. This leads to neurotization, which can turn into a mental epidemic. Because of this, any event that unbalances the social system can turn into destructive behavior of the masses. The danger of such detente is increasing in the modern information society. As a conclusion, it is noted that "Shadow" acts as a moral problem that challenges the "I" and is unconscious without moral effort. Therefore, the first step towards its realization is recognition of the reality of its dark sides.

Key words: collective unconscious, archetype "Shadow", violence, destruction, mass society, information society. 
For citation: Sidorenko I. N. Archetypes of the collective unconscious and the problem of violence in philosophy of C. Jung. Proceedings of BSTU, issue 6, History, Philosophy, 2021, no. 1 (245), pp. 134137 (In Russian).

Введение. Проблематика антропологии насилия, а именно раскрытие экзистенциальноантропологического модуса, находит свое отражение в анализе и разрешении проблемы «раздвоенности» человеческой природы и дихотомии подлинного и неподлинного отчужденного существования человека. Зигмунд Фрейд, анализируя формы самодеструкции как акты насилия, обнаружил в них эротический элемент, т. е. инстинкт разрушения сопровождается повышенным уровнем нарциссического наслаждения, основывающегося на удовлетворении желания господствовать над природой. В силу этого сущностной чертой деструкции как насилия над природой человека становится удовлетворение инстинкта наслаждения через разрушение. О насилии как деструкции в совершенно ином ключе, однако в рамках пространства психоанализа, писал швейцарский ученый Карл Юнг.

Основная часть. Наравне с индивидуальным бессознательным К. Юнг отметил наличие и значимость коллективного бессознательного, которое представляет не просто склад влечений и инстинктов, но и является источником будущих идей и психических состояний. Основное содержание коллективного бессознательного составляют архетипы, т. е. своеобразные манифестации глубинных слоев бессознательного, всеобщие, свойственные всему человечеству когнитивно-чувственные образы-образцы как отражение зафиксированного в глубинах психики опыта человечества. Архетип оказывает колоссальное влияние на поведение человека, народа, так как он «несет в себе некое особое "влияние" или силу, благодаря которой воздействие его носит нуминозный, т. е. зачаровывающий либо побуждающий к действиям характер» $[1$, с. 76]. Несмотря на всеобщность архетипов, их бессознательное содержание изменяется, «когда оно становится осознанным и воспринятым, и использует краски индивидуального сознания, в котором оно проявляется» [2, с. 174]. Поэтому архетип есть неизменная форма, получающая свое изменчивое историческое воплощение в зависимости от типа общественного развития. Однако на любом историческом этапе архетип функционирует как часть личности.

Деструктивность природы человека К. Юнг связывал с возникновением и развитием общества массовой культуры, на этапе реализации которого архетип «Тень» начинает играть доминирующую роль. «Тень» представляет собой оборотную негативную сторону человека, нации, которая скрыта ото всех, т. е. это те аспекты личности, которые человеком/группой отвергаются и подавляются. Таким образом, «Тень» выступает в качестве моральной проблемы, бросающей вызов «Я» и неосознаваемой без нравственных усилий. Первый шаг к осознанию - это признание реальности своих темных сторон [3]. Архетип «Тень» функционирует следующим образом: то, что не нравится - отрицается, не замечается, потом подавляется и в подавленном состоянии ищет аффект для разрешения или порождает невротическое состояние, одновременно проецируется на другого, т. е. в других видится то, что не замечается в себе. В массовом обществе архетип «Тень» воплощает все базовые инстинкты и ищет выхода для разрядки в различных формах насилия.

Главной характеристикой массового общества, с точки зрения К. Юнга, является потеря гармонии сознания с бессознательным, что выражается как в массовизации сознания и поведения людей, растворения личности в толпе, так и в ощущении внутренней дисгармонии. Причиной нарушения психического баланса выступает тотальная рационализация и формализация общественных отношений. Игнорирование и подавление бессознательного требует компенсации: стремление снять невроз как за счет идентификации индивидуального сознания с коллективным, так и посредством сублимации иррациональных влечений. Результатом такой компенсации выступает псевдополитическая активность, которая не предполагает разумного выбора и осознанного действия, a, наоборот, предстает как реакция, подчиняющаяся требованию: «Действуй, не думай!». В массовом обществе этот невроз получает форму психической эпидемии, «всеобщей политизации общественной жизни», требующей выхода в создании политических движений [3]. Политическое движение концентрирует в себе огромный психический заряд посредством концентрации коллективного бессознательного и его подавления. В силу чего любое событие, выводящее из равновесия социальную систему, грозит обернуться и оборачивается разрушительным поведением масс. Опасность такой разрядки повышается в современном информационном обществе.

Информационное общество не только делает социальную жизнь более комфортной, наполненной и активной из-за доступности информации, расширения информационного пространства и коммуникационных возможностей, оно 
не только связано со становлением «общества знания», но и порождает новые проблемы, такие как угроза манипулирования сознания и тотального контроля посредством информационных технологий; дефицит информации или ее избыточность; проблема полноты и объективности информации и т. д. Манипулирование информацией увеличивает риск деформации процесса принятия решения, грозящий радикальным обострением международной ситуации. На основании этого одной из главных опасностей и, к сожалению, уже тенденций современного общества является информационное насилие, которое правомерно определить как подавление и бессознательное подчинение индивида, группы, сообщества посредством информационных технологий. Так, например, Интернет подчас является пространством для осуществления так называемой «политики скандалов»: намеренной дезинформации, информационной мистификации, кибератак. Информация никогда не бывает полной, в этом и кроется опасность насилия: индивид на веру принимает те сведения, новости, рекламу, которые соответствуют его установкам и предпочтениям или подаются как научная информация из авторитетного источника. Именно так осуществляется скрытая сила информационного насилия, которое использует в качестве средств полит- и пиар-технологии [4]. Это не означает, что информационное насилие порождение современного общества, нет, оно было всегда, однако благодаря современным информационным технологиям оно претендует на то, чтобы быть глобальным.

Внутренняя дисгармония и комплекс неполноценности с необходимостью приводят к трансформации массового общества в тоталитарное, механизмы осуществления которого К. Юнг обозначил как «психическую инфляцию» и «психическую дефляцию» [3].

Что касается психической инфляции, то она есть результат идентификации субъекта(ов) власти с коллективным бессознательным и наделением им(и) себя сверхчеловеческими качествами как компенсацией неполноценности. Парадокс заключается в том, что приписывание себе сверхчеловеческих качеств приводит к более острому переживанию своей неполноценности и, как следствие, усилению жажды новой сверхкомпенсации.

Психическая дефляция, напротив, в качестве своего источника имеет чувство неполноценности, которое переживает масса (при переносе силы бессознательного на вождя). Только в этом случае уже масса испытывает бессознательную жажду власти, однако утолить ее она может только посредством идентификации с вождем. Порочный круг есть и в реализации психической дефляции: чем сильнее масса ощущает себя неполноценной, тем более жесткой и могущественной власти она требует. Круг замкнулся: вождь и масса невозможны друг без друга. Поэтому тиранический субъект власти с помощью различных форм насилия «подпитывает» комплекс неполноценности массы, порождая ответный всплеск насилия еще большего масштаба, и так по нарастающей.

В свою очередь расширение кругов насилия создает взрывоопасную ситуацию, грозящую как самому властному субъекту, так и обществу в целом. Решение этой проблемы иррационально: бессознательно тиранический субъект «овладевает» архетипом (например, Отца, Мудреца, Матери и т. п.) и на его основе осуществляет сплочение общества. Для сохранения интеграции массы в единство необходим еще враг. С этим масса хорошо справляется и сама: отрицая в себе негативные стороны, склонность ко злу и насилию и т. п., она оправдывает себя тем, что в акте проекции не только переносит все эти отрицаемые качества на другого (народ, государство, нацию), но и возлагает на них ответственность за проявление негативных тенденций в социуме. Именно с этими процессами К. Юнг связывал германский национал-социализм, «одурманивание» немцев «великой» идеей.

Вместе с тем нацизм, с точки зрения К. Юнга, является негативным примером отрицания коллективного бессознательного. Угроза теневых проекций и насилия существует и после поражения нацизма. Следуя мысли К. Юнга, правомерно отметить следующие основания этой угрозы: 1) самоценность государства и низведение личности до его функций; 2) пренебрежение коллективным бессознательным; 3) комплекс неполноценности; 4) конструирование образа врага; 5) «Тень» инстинктивно вытесняется в подсознание, «делая его психически больным». Игнорирование и подавление бессознательного не только приводит к тотальной рационализации, оборачивающейся безумием, и формализации общественных отношений, но и грозит психической эпидемией в виде «всеобщей политизации жизни». Следовательно, насилие - это результат больного подсознания, его деструкции. Массовое общество свои неврозы излечивает радикальным способом: с помощью революций и войн. В силу этого К. Юнг пессимистично оценивал возможность окончательного мира. Естественным является состояние войны, что же касается абсолютного мира, то это скорее противоестественно, так как попытка его установления приведет к тотальному подавлению влечений человека. В результате произойдет накопление отрицательной энергии, которая неизбежно приведет к взрыву. 
Заключение. Несмотря на пессимизм К. Юнга, исходя из его идей, правомерно сконструировать сценарий минимизации насилия. Во-первых, это поиск баланса, преобразовывающего иррациональные влечения и агрессивные инстинкты. В качестве таковой в концепции К. Юнга предстает модель западной демократии. Она не лишена недостатков, в частности не спасает от обезличивания человека в государстве, однако представляет собой тот противовес, позволяющий не разгораться огню насилия, а еле тлеть под видом «умеренной» гражданской войны или анархии. Во-вторых, это восстановление психического здоровья народа за счет реализации психоаналитических шагов: 1) признание коллективной вины; 2) искреннее покаяние; 3 ) осознание бессознательного или «работа с Тенью». То есть, признание существования темных сторон способно остановить их деструктивное влияние.

Таким образом, в психоаналитической философской концепции К. Юнга была раскрыта связь деструктивной природы человека с возникновением и развитием общества массовой культуры и актуализацией архетипа «Тень», который воплощает базовые инстинкты и ищет выход для разрядки в различных формах насилия, что дало возможность определить насилие как результат игнорируемого бессознательного, его деструкции. В силу этого правомерен вывод о том, что общество массового потребления превращается в общество тотального насилия. В качестве сценария преодоления насилия был предложен следующий: «работа с Тенью» как осознание своих темных сторон.

\section{Список литературы}

1. Юнг К. Г. Очерки по психологии бессознательного. 2-е изд. М.: Когито-Центр, 2010. 352 с.

2. Юнг К. Г. Архетип и символ. М.: Ренессанс, 1991. 343 с.

3. Юнг К. Г. Эон: исследования о символике самости. М.: Академический Проект, 2009. 340 с.

4. Сидоренко И. Н. Информационное насилие в эпоху глобализации // Международная журналистика - 2014: диалог культур и взаимодействие медиа разных стран: материалы III Междунар. науч.практ. конф., Минск, 20 февр. 2014 г. / Белорус. гос. ун-т. Минск, 2014. С. 244-252.

\section{References}

1. Jung K. G. Ocherki po psikhologii bessoznatel'nogo [Essays on the psychology of the unconscious]. 2nd ed. Moscow, Kogito-Tsenter Publ., 2010. 352 p.

2. Jung K. G. Arkhetip i simvol [Archetype and symbol]. Moscow, Renessans Publ., 1991. 343 p.

3. Jung K. G. Eon: issledovaniya o simvolike samosti [Eon: research on the symbolism of the self]. Moscow, Academicheskiy Proyect Publ., 2009. 340 p.

4. Sidorenko I. N. Information violence in the era of globalization. Materialy III Mezhdunarodnoy nauchno-prakticheskoy konferentsii ("Mezhdunarodnaya zhurnalistika-2014": dialog kul'tur i vzaimodeystviye media raznykh struktur) [Materials of the Third International scientific and practical conference ("International Journalism - 2014: dialogue of cultures and the interaction of the media of different countries")]. Minsk, 2014, pp. 244-252 (In Russian).

\section{Информация об авторе}

Сидоренко Ирина Николаевна - доктор философских наук, доцент, профессор кафедры философии и методологии науки. Белорусский государственный университет $(220050$, г. Минск, ул. Кальварийская, 9, Республика Беларусь). E-mail: iri_na2000@rambler.ru

\section{Information about the author}

Sidorenko Irina Nikolayevna - DSc (Philosophy), Assistant Professor, Professor, the Department of Philosophy and Methodology of Science. Belarusian State University (9, Kal'variyskaya str., 220050, Minsk, Republic of Belarus). E-mail: iri_na2000@rambler.ru 